\title{
Preliminary fixed-bed downdraft gasification of birch woodchips
}

\author{
S. Sarker $\cdot$ H. K. Nielsen
}

Received: 16 March 2013/Revised: 17 March 2014/ Accepted: 10 May 2014/Published online: 3 June 2014

(C) Islamic Azad University (IAU) 2014

\begin{abstract}
This paper investigated the possibilities of using birch wood chips for fixed-bed downdraft gasification. The preliminary air gasification resulted producer gas with an average composition of $11.5 \% \mathrm{CO}, 5.4 \% \mathrm{CO}_{2}$, $5.9 \% \mathrm{H}_{2}, 0.38 \% \mathrm{CH}_{4}$ corresponding to a mean lower heating value of about $2 \mathrm{MJ} / \mathrm{kg}$. The approximate size of woodchips used for gasification was around $11.5 \mathrm{~mm}$ for a maximum solid throughput of $0.65 \mathrm{~kg} / \mathrm{h}$. The obtained equivalence ratio (ratio between actual air fuel ratio and stoichometric air fuel ratio) as a result of air and biomass feed was close to 0.45 which was stable throughout the test. Producer gas left the gasifier at ca. $150{ }^{\circ} \mathrm{C}$ and was diverted for flaring owing to the level of low energy content. Despite availability, the option for gas to generate heat and electricity via integrated gas engine has not been utilized in the present case and remained for further ongoing research.
\end{abstract}

Keywords Birch wood · Fixed-bed · Downdraft · Gasification · Producer gas

\section{Introduction}

The global energy is running the risk of scarcity and phase out of fossil fuel in the coming future (Shafiee and Topal 2009; Zainal et al. 2002). This will cause the utilization of various energy sources including with the renewables in all aspects of societies and industries. Mobilizing energy

S. Sarker $(\bowtie) \cdot$ H. K. Nielsen

Faculty of Engineering and Sciences, University of Agder, 4898

Grimstad, Norway

e-mail: shiplu.sarker@uia.no sectors toward sustainable and renewable technologies are a revolutionary stride expected to yield pronounced benefits in the context of energy security, reliability and environmental emissions (Ahmed et al. 2011). Gasification of biomass is one promising candidate to successfully achieve this transformation. By gasification, solid biomass gets converted into combustible gas with a typical composition of $\mathrm{CO}, \mathrm{CO}_{2}, \mathrm{H}_{2}, \mathrm{CH}_{4}, \mathrm{~N}_{2}$ and a trace amount of inert components (Hindsgaul et al. 2000; Barman et al. 2012), which has enormous potential to be utilized into range of applications (Brown and Brown 2013; Gautam 2010). Biomass with many different types is viable for gasification, but wood is particularly preferred due to its characteristics superior over coal and many grassy biomass as exemplified by high volatiles, low sulfur and low ash content (Janajreh and Al Shrah 2013; Shul'ga et al. 2012). Graphically, the convenient properties of wood in respect of other solid fuels has been depicted in popular Van krevelen diagram and cited by number of researchers (Janajreh and Al Shrah 2013; Basu 2010; Barrio 2002). Considering that, present work is based on one class of wood such as birch (Betula Pendula), as a feedstock for gasification.

Birch is abundant in northern European climate (Grønli 1996), but predominantly used for household applications as firewood to meet the heat demand. So far, utilizing birch for combustion contributed to a number of emissions leading to environmental and health hazards (Hedberg et al. 2002). These drawbacks pose a great concern triggering in search for alternative that could sustainably be applied for energy production. Gasification in that direction consequently emerged as a viable solution to diminish much of the issues associated with combustion. Unlike combustion which requires equal or higher amount of stoichiometric air, gasification occurs at oxygen scarce 
condition and hence contributes to a significant reduction in pollutant emissions. For this study, therefore, gasification of birch woodchips is proposed which to date has not been exploited to the knowledge of the authors.

In general, thermochemical conversion of biomass is performed into three different types of gasifiers commonly known as fixed-bed, fluid-bed and entrained flow reactors (Kotowicz et al. 2013; Couto et al. 2013). Fixed-bed reactors are further categorized into updraft, downdraft and cross-draft gasifiers based on the way feedstock and gas move through the system. Within the fixed-bed reactors, downdraft technologies offer several advantages that include: simplicity in construction (Wei 2010), suitability for small scale applications (Asadullah 2014) and the possibilities of generating less tar (McKendry 2002; Son et al. 2011; Chopra and Jain 2007) as a result of hot gas passing through the high-temperature zone of the reactor. Based on these premises, the present work investigated air gasification of fixed-bed downdraft gasifier utilizing wood as feedstock.

Experimental investigation of fixed-bed downdraft gasification of woodchips has been explored in many contemporary works. Lenis et al. (Lenis et al. 2013), for example, focused on five different wood species (Acacia mangium, Eucalyptus sp., Pinus sp., Pinus patula and Gmelina arborea) for which first the gasification model was formulated which was further validated in a lab scale reactor. Lee et al. (2013) developed their studies based on fixed-bed air gasification and further to electricity generation via spark ignition internal combustion (IC) engine using pine and red oak as feeding materials. Fixed-bed downdraft gasification of woodchips with air as gasifying agent was performed by a comprehensive research conducted by Zainal et al. (2002) who established the effect of operational parameters on the quality and quantity of producer gas. Published research (Yoon et al. 2011) also included the influence of several parameters on fixed-bed gasification of woodchips (German Conifer) using air and steam mixtures as the gasifying medium.

In line with those previous contributions, biomass energy research group at University of Agder is facilitating the fundamental components necessary for gasification and subsequently for energy production. This paper only reports the preliminary work which was devoted to examine the possibilities of utilizing birch wood chips for fixed-bed gasification with air as gasifying agent.

\section{Materials and methods}

Date and location of the study: 08/08/2013, University of Agder, Grimstad, Norway.
Feedstock

Birch wood was cut down by a chain saw and further chipped by a disk chipper (NHS 720 IE 4, Denmark) with a nominal cutting length of about $11.5 \mathrm{~mm}$ during the winter 2012-2013 at Grimstad, Norway. Produced wood chips were then placed indoor, stacked with a $20 \mathrm{~cm}$ thick layer for natural drying, which was promoted by repeated mixing with shovel. The photograph of birch woodchips is illustrated in Fig. 1.

\section{Characterization of birch woodchips}

Birch woodchips was characterized for moisture, proximate, ultimate and heating value analysis prior to gasification. Moisture was determined in situ gravimetrically with a moisture analyzer (Metler Toledo LJ16, Switzerland) programmed for $105{ }^{\circ} \mathrm{C}$ temperature. By this instrument, total weight loss of a sample is measured with corresponding increase in temperature until no further weight measurement at the set temperature. Volatiles were determined by the external lab Eurofins Environmental Testing Sweden AB according to the protocol EN $15148 / 15402$. Ash was measured complying with the standard CEN/TS 15403, whereas fixed carbon was evaluated by difference. Calorific value of feedstock was measured in situ employing bomb calorimeter (LECO AC 500, USA) that followed the standard CEN/TS 14918/15400 ISO. Likewise volatiles, elemental analysis of birch wood was also conducted externally by Eurofins Environmental Testing Sweden AB according to the protocol EN 15104/15407 for carbon, hydrogen, oxygen and nitrogen and according to the protocol EN 15289/15408 for chlorine $(\mathrm{Cl})$ and sulfur $(\mathrm{S})$. The characterization of birch woodchips in respect of proximate and ultimate analysis is presented in Table 3.

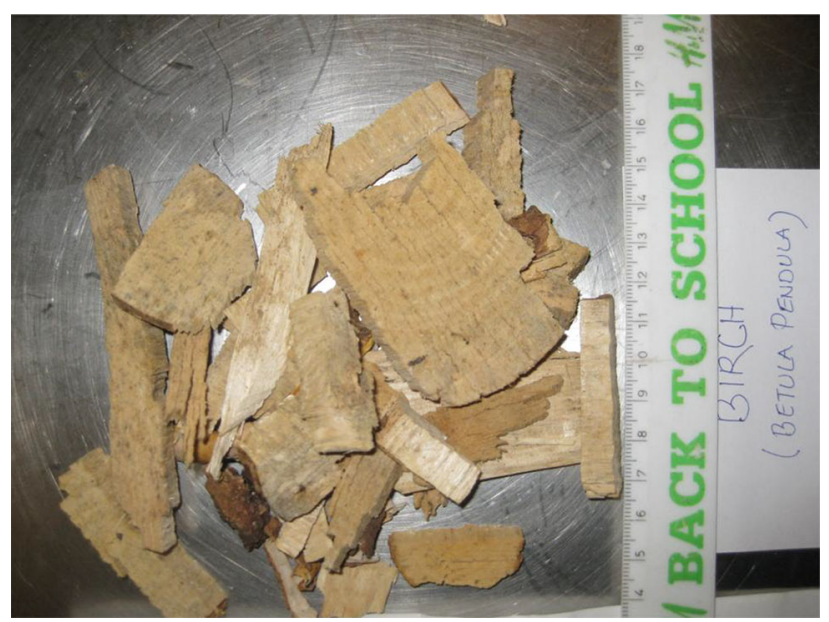

Fig. 1 Birch woodchips used for gasification 
Fig. 2 Flaring of fixed-bed downdraft gasifier integrated with a natural gas engine (University of Agder)

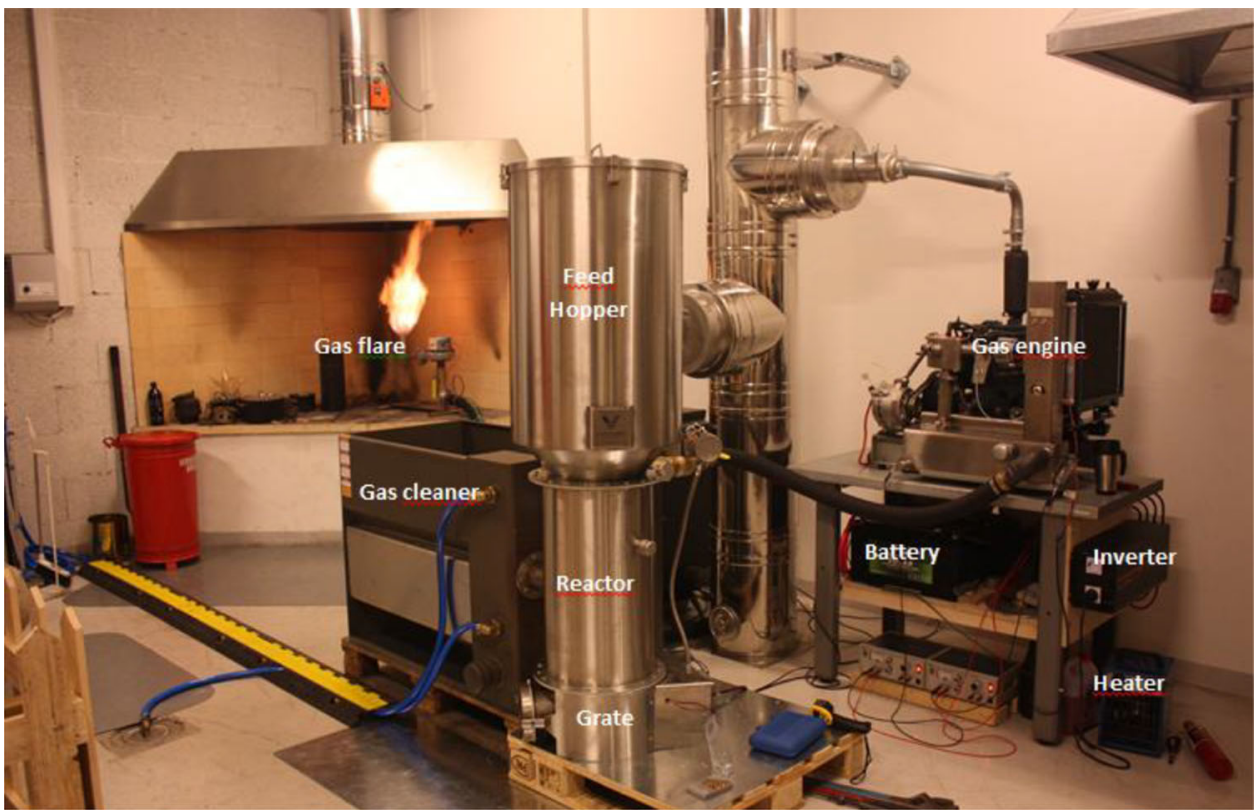

Table 1 Specifications of the gasification unit: source Victory Gasworks

\begin{tabular}{ll}
\hline Item & Description \\
\hline Gasifier & Victory super CHP \\
Type & Air blown downdraft gasifier \\
Input & $\sim 1.13 \mathrm{~kg} / \mathrm{kWh}$ \\
Maximum speed & $4-90 \mathrm{~m}^{3} / \mathrm{h}($ adjustable) \\
Output with engine & $5-15 \mathrm{~kW}_{\mathrm{e}}, 3 \mathrm{~kW}$ hot water \\
Operating temperature & $1,050-1,250{ }^{\circ} \mathrm{C}$ \\
\hline
\end{tabular}

\section{Experimental setup}

\section{Gasifier and engine}

The experimental setup consists of a fixed-bed downdraft Victory gasifier unit with integrated hopper, producer gas cooling and cleaning system. The specification of gasifier is given by the Table 1, whereas Fig. 2 shows the structure of the gasifier system. The gasification unit comprises with a $0.13-\mathrm{m}^{3}$ cone structure feeding hopper above the reactor.

Main body of this structure is made from a $500-\mathrm{mm}$ outer diameter steel pipe with an internal air jacket and refractory insulation in reaction zone. Total height of the gasifier including with the hopper is around $1.7 \mathrm{~m}$. The inclined shape of the hopper ensures the smooth gravitational flow of feeding material into the throat for better gasification and tar reduction. Biomass is fed from the top, while the air is induced through six nozzles above an exchangeable restriction ring $(100 \mathrm{~mm})$. Nozzles are equidistantly located around the circumference of pipe above the throat of the gasifier. To provide a sufficient draft
Table 2 Specifications of the gas engine: source Kubota Engine America Corporation

\begin{tabular}{ll}
\hline Item & Description \\
\hline Engine & Kubota DG972-E2 \\
Type & Vertical 4-cycle liquid cool natural gas \\
No. of cylinders & 3 \\
Maximum speed & $3,600 \mathrm{rpm}$ \\
Volume & $0.962 \mathrm{~m}^{3}$ \\
Output (natural gas) & $17.6 \mathrm{~kW}$ \\
\hline
\end{tabular}

necessary for the air to pass through the system, a fan is located at the end of gas exit and powered by a battery bank charged by a gas engine (for this experimental set up). In a typical case, producer gas exiting from gasifier runs the engine and gets converted into heat and electricity which is subsequently stored in a lead-acid battery for further usage (Fig. 2).

Biomass as moves downward from the top of the gasifier is dried and devolatilized by the heat carried from the combustion zone. High-temperature gas from the combustion zone is gasified by the gas and solid phase reactions and exits from the bottom of the gasifier. After passing the gasifier, the producer gas is cooled in a gas-water heat exchanger, resulting in condensation of a portion of water vapor. Additional gas cleaning is achieved in a settling chamber filled with hanging ribbons while final cooling and filtration is conducted by a water sprayed Teflon filter screen sieve. While leaving the gasifier, the producer gas also comes into contact with the glowing char and the ashes and as a result provides the additional cleaning effect. Char produced through the thermochemical reaction is also 


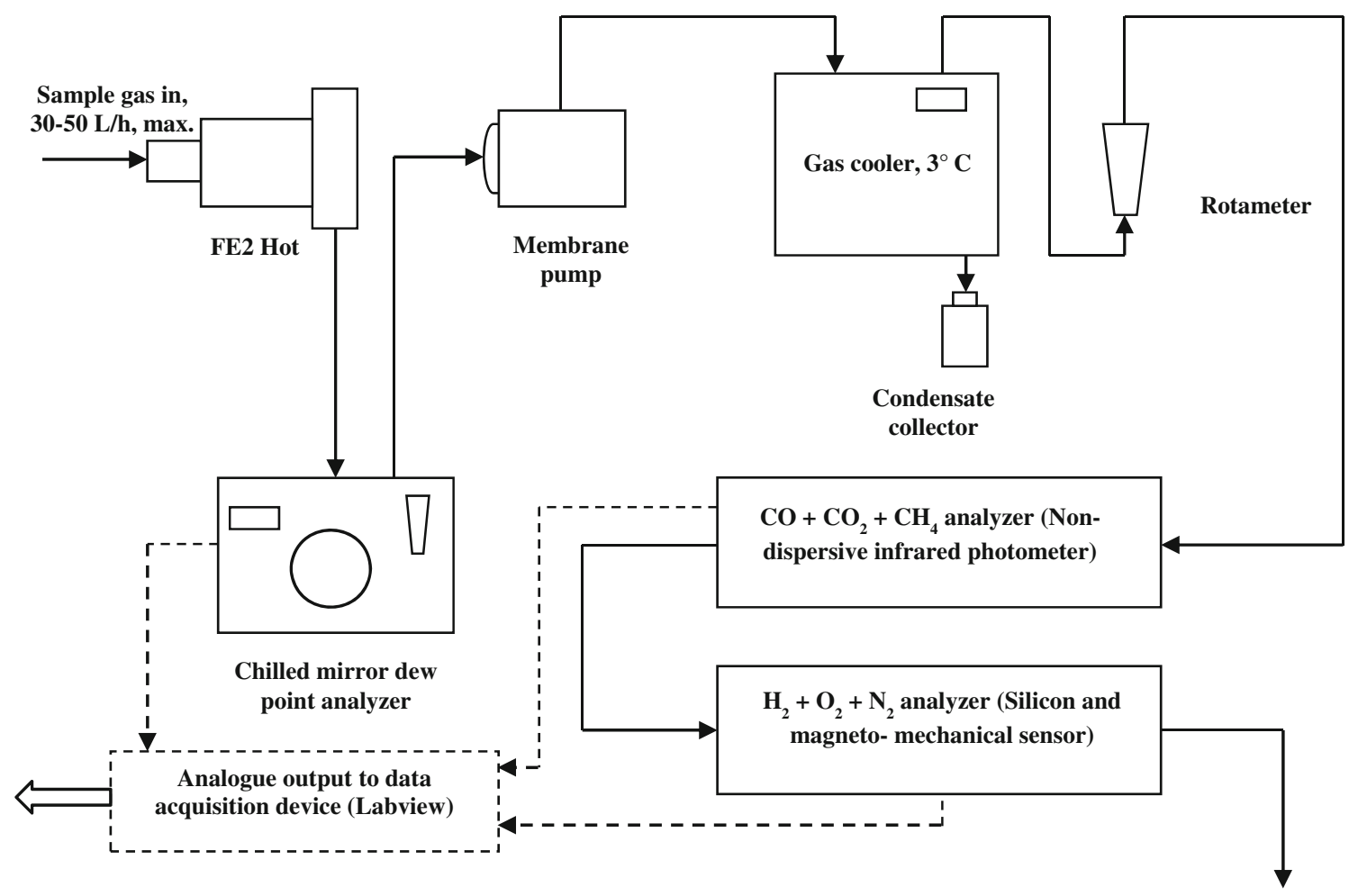

Fig. 3 Components used in gas sampling and data acquisition

gasified by high temperature ( $\sim 900-1,000 \mathrm{~K}$ ) (Jayah et al. 2003) and generates necessary heat to propagate the gasification steps throughout the reactor. Ash, the final solid product of gasification with a very little value for combustion and gasification, is collected from the grate, positioned beneath the combustion chamber. Cleaned producer gas is by-passed for flaring to identify the quality before diverting to the gas engine. Flame in the flare turns from bright yellow to bluish (corresponding to the high energy content gas) once the producer gas is ready for consumption in the gas engine.

The gasifier is also featured with a vibrating mechanism, a shaker, driven by an electric motor to generate the vibration motions at a regular interval. Such vibrations reduce the risk for channeling and bridging of biomass inside the gasifier and sustain the continuous downward movement of feedstock. The grate is reciprocally rotated by adjustable intervals for a smoother and easier ash discharge.

Further downstream, the gasifier is coupled with a $0.962 \mathrm{~L}$ three cylinder natural gas engine rated with $17.6 \mathrm{~kW}$ mechanical power. The engine is capable to run at a wide range of speed up to 3,600 $\mathrm{rpm}$. In the present case, the engine generates electricity in two DC generators with a total capacity of $5 \mathrm{~kW}$. The electricity is stored in the battery which with the help of an inverter subsequently transforms DC power into AC which is further utilized by an adjustable load of $5.3 \mathrm{~kW}$ (electric heaters). The specifications of engine as per Kubota Engine America Coroporation is illustrated in Table 2.

\section{Gas sampling}

In order to measure and monitor the composition of the producer gas, a part of the gas is bypassed at a maximum flow rate of $50 \mathrm{~L} / \mathrm{h}$ through the state-of-the art gas sampling facility consisting with hot filter, dew point analyzer, membrane pump, rotameter, gas cooler and gas analyzers as demonstrated in Fig. 3. In the first step, dust particles are removed from gas by the hot filter (FE2, ABB, Germany) operating at a temperature of around $150{ }^{\circ} \mathrm{C}$. The relatively cleaned gas is then flown through a dew point analyzer (Omega, RHB-1500, USA) for determining the dew point, necessary for evaluating dryness of the gas. Subsequently, gas is partially dried by supplying through a gas cooler (SCC-C Sample gas cooler, ABB, Germany), maintaining about $3{ }^{\circ} \mathrm{C}$ temperature at outlet. Flow into the sampling line is maintained by a diaphragm pump (Membrane pump $4 \mathrm{~N}, \mathrm{ABB}$, France) and controlled by a rotameter $(0-50 \mathrm{~L} / \mathrm{h})$, governing the flow at a desired level. After cleaning and drying via hot filter and gas cooler, the gas is finally sent to the analyzers. In principle, gas analyzer detects the gas composition within the flow range of $20-40 \mathrm{~L} / \mathrm{h}$ which is monitored by the rotameter located into the flow line. Two analyzer units (Advance optima, AO2020; ABB, Germany) mounting three different sensors 
(URAS 26, CALDOS 27 and MAGNOS 206) measure various composition of producer gas. Gas analyzer unit 1 houses analyzer component URAS 26, working with the principle of non-dispersive infrared photometer and measures percent composition of $\mathrm{CO}, \mathrm{CO}_{2}$ and $\mathrm{CH}_{4}$ in the producer gas. Analyzer unit 2 contains two sensors CALDOS 27 and MAGNOS 206 and determines the percent amount of $\mathrm{H}_{2}$ and $\mathrm{O}_{2}$ in the sample gas content. Sensor CALDOS 27 uses the concept of high thermal conductivity of $\mathrm{H}_{2}$ for gas measurement, while paramagnetic nature of oxygen is utilized in MAGNOS 206 to analyze oxygen in the sample gas flow.

\section{Analytical}

Produced gas composition after gasification was evaluated in situ by the ABB gas analyzers as specified in "Gas sampling" section, whereas the lower heating value was calculated based on the procedure set by ISO 6976. Temperature at different locations of gasifier, air and gas was measured by the number of K-type thermocouples mounted in and around the gasifier. Two pressure sensors (Smart DCM/SN Diff, Fema, Germany) measure the pressure difference in the process as a result of filtration (hot and wet) and obstruction in the gas and biomass. Figure 4 shows the location of four temperature sensors: $\mathrm{T}_{1}$ (at reduction), $\mathrm{T}_{2}$ (gas exit), $\mathrm{T}_{3}$ (combustion) and $\mathrm{T}_{5}$ (air inlet) and one pressure sensor, $\mathrm{p}_{1}$ within the gasifier. $\mathrm{T}_{4}$ (filtered gas) and $p_{2}$ are located in the downstream of the gas flow and therefore are not covered in Fig. 4. Degradation of feed during gasification was monitored by a scale (Dini Argeo, DGT PK, Italy) installed beneath the gasifier assembly. The values registered in the scale, gas analyzers, temperature sensors, pressure sensors and dew point analyzer were acquired through Labview data acquisition software (National Instruments, LabVIEW 2010, USA) for further interpretation. Screen shot of Labview programming is given in the "Appendix".

\section{Results and discussion}

\section{Feedstock characterization}

Results of feedstock characterization (Table 3) demonstrated that the level of moisture in birch woodchips is acceptably low which in terms of gasification is very attractive (Atnaw et al. 2014; Gautam 2010). Additionally, birch has low ash, low sulfur, low chlorine and high calorific value and high volatile matter content as reflected in Table 3. Woody biomass exhibiting such composition possibly yields less or no tar in the produced gas within the operating scale that does not exceed $30 \mathrm{~kW}$ as evidenced

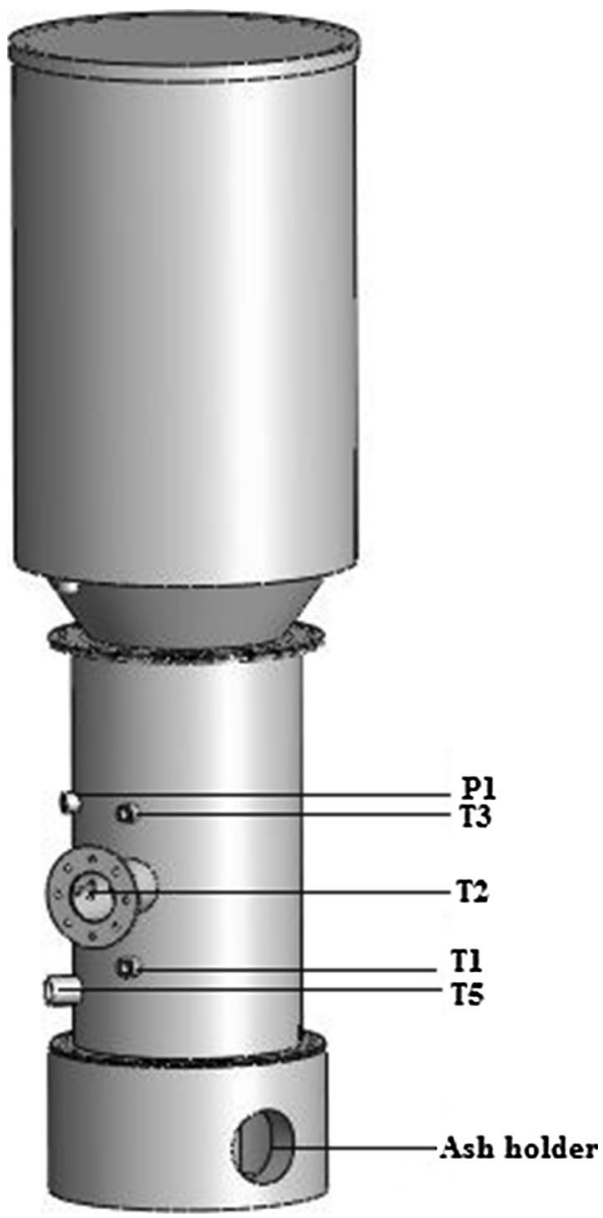

Fig. 4 Pressure and temperature sensors along the gasifier

by (Son et al. 2011; Warren et al. 1995). Moreover, low ash offers substantial advantages in reducing the potential of slagging and slow biomass conversion, as discussed by (Rajvanshi 1986). High carbon content (50.4\%) furthermore suggests why the calorific value of this biomass is rather high (Moka 2012). Knowing the physical and chemical composition of biomass is of great importance to understand the gasification phenomena associated with reaction chemistry, gas composition and tar characteristics further can be extrapolated for energy and mass balance of the entire system.

\section{Gasification of birch wood chips}

Among the range of operations, trial run of gasifier with $100 \%$ birch wood chips (moisture content $15.2 \%$ ) that carried on August 8, 2013, was most interesting in terms of fuel gas composition and calorific value. The experiment continued for about $6 \mathrm{~h}$ during which period several experimental parameters such as characteristics of producer gas, gas flow, temperature and pressure at different 
Table 3 Proximate and ultimate analysis of birch woodchips

Proximate analysis (dry basis)

Moisture, \%

Volatiles, $\%$

82.2

Fixed carbon, \%

10.45

Ash, \%

0.35

LHV (MJ/kg)

17.9

Ultimate analysis (dry basis)

Carbon, \%

50.4

Hydrogen, \%

Oxygen, $\%$

43.4

Nitrogen, $\%$

0.12

Sulfur, \%

0.017

Chlorine, \%

locations and biomass feed degradation pattern are measured and illustrated in Fig. 5 through 7.

Figure 5 demonstrates the evolution of producer gas composition and its corresponding LHV (Lower heating value) throughout the test period. Among the combustible species of generated gas, $\mathrm{CO}$ was found highest with an average of $11.8 \%$, followed by hydrogen $(5.9 \%)$ and methane $(0.38 \%)$. Gas LHV, a direct function of combustible components, reached to a peak at approximately $2.5 \mathrm{MJ} / \mathrm{kg}$ when reasonably higher $\mathrm{CO}$ and $\mathrm{H}_{2}$ were produced after some $4 \mathrm{~h}$ of operation. However, the trend was varying to a great degree, characterized by few unstable periods close to second, third and fifth $h$ of operation. These phenomena are perhaps attributed to a several factors such as bridging, abrupt change in temperature (Zainal et al. 2002), instability in air supply (Reed et al. 1988). In fact, the decrease in airflow during the unstable periods was clearly observed and evidenced by Fig. 6. Generally, the decrease in battery voltage causes the decrease in fan speed which ultimately reflects in air flow and in turn in gas pressure, biomass conversion, temperature and gas characteristics, as indicated by Fig. 5 through 7 . While other parameters were influenced, airflow resulted an average equivalence ratio (ER) of 0.45 which is arguably high for gasification. By and large, downdraft gasification was proved to perform better when operated within the range of 0.25 ER (Reed et al. 1988). The study of (Zainal et al. 2002), however, showed the successful operation even with an ER up to 0.43 . Likewise equivalence ratio, mean cold gas efficiency for this experiment was relatively low, approximately to $54 \%$. Typical cold gas efficiency for fixed-bed downdraft gasifier lies in the range between 65 and $75 \%$ as reported by (Knoef et al. 2012). Cold gas efficiency for this work could probably be improved by increasing airflow eventually contributing to the reaction chemistry between gas and solid components, causing high composition of combustible species in the producer gas.

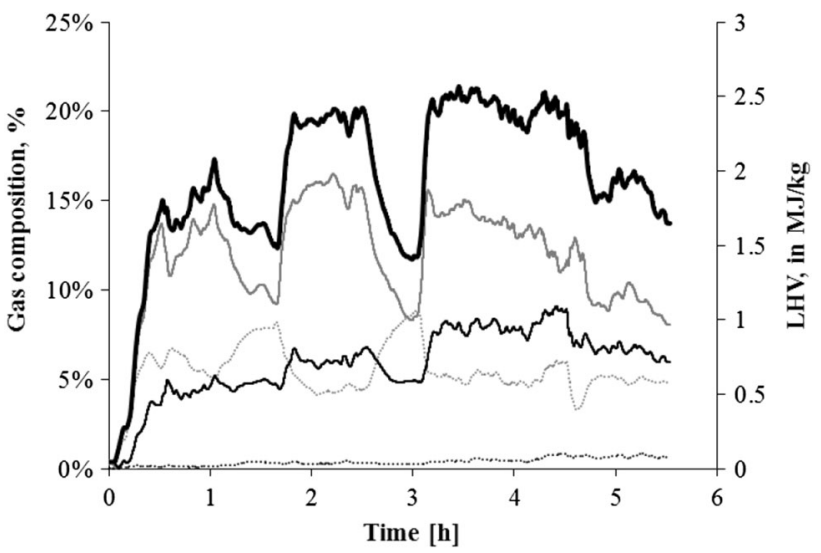

Fig. 5 Composition of producer gas and its corresponding calorific value: LHV (Thick solid black line); $\mathrm{CO}$ (Solid gray line); $\mathrm{CO}_{2}$ (Dotted gray line); $\mathrm{H}_{2}$ (Thin solid black line); $\mathrm{CH}_{4}$ (Dotted black line)

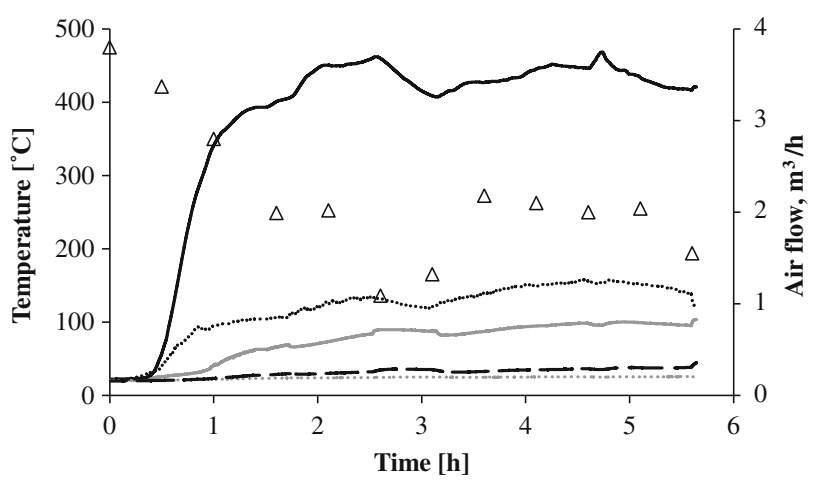

Fig. 6 Temperature at different gasifier locations and airflow: $T_{1}$, reduction (Solid gray); $\mathrm{T}_{2}$, raw gas exit (Dotted black); $\mathrm{T}_{3}$, combustion (Solid black); $\mathrm{T}_{4}$, filtered gas exit (Dotted gray); $\mathrm{T}_{5}$, air inlet (Dashed black); airflow (empty triangles)

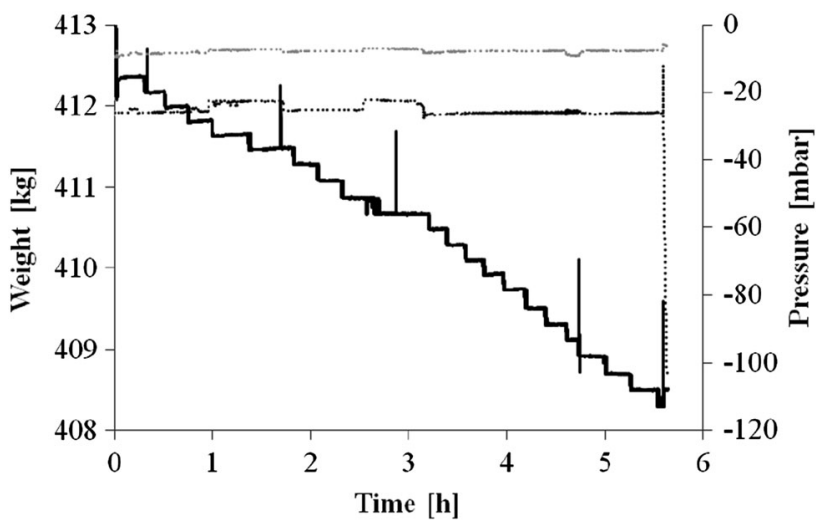

Fig. 7 Biomass degradation and pressure gradient during gasification of birch wood: Weight reduction (Solid black line); p1, pressure before filtration (Dotted black line); p2, pressure after filtration (Dotted gray line)

Principally, air is the only external input that can be varied while gasifier is under operation and thus leaving a wide scope for further investigation at a numerous air inputs. 
The basic idea of this preliminary study was to evaluate the performance of measurement system that generates necessary operational and technical data from gasification. So observing the nature and relation between parameters as illustrated by Fig. 5 through 7 would provide a solid basis for further improvement in technical and theoretical aspects which include optimization of process parameters, evaluation of tar, experimentation on power production.

\section{Conclusion}

This study revealed the performance of a downdraft fixedbed gasifier for producing high energy gas by utilizing birch woodchips as a feedstock. In the preliminary run, the LHV of the producer gas reached to maximum $2.5 \mathrm{MJ} / \mathrm{kg}$ with a corresponding ER of 0.45 . The average product gas composition (11.5\% CO, $5.4 \% \mathrm{CO}_{2}, 5.9 \% \mathrm{H}_{2}, 0.38 \%$ $\mathrm{CH}_{4}$ ) and the cold gas efficiency (54\%) were nevertheless found low, suggesting a wide scope of performing more research on birch wood gasification. The present research thus is ongoing and yet to discover the heat and electricity potential of wood gas by incorporating gas engine as a downstream energy conversion unit.

Acknowledgments The authors greatly acknowledge the $\mathrm{PhD}$ funding and the facilities of University of Agder together with J.B.Ugland AS to conduct this research. Assistance from a number of people during biomass harvesting and pre-treatment is also highly noted.

\section{Appendix}

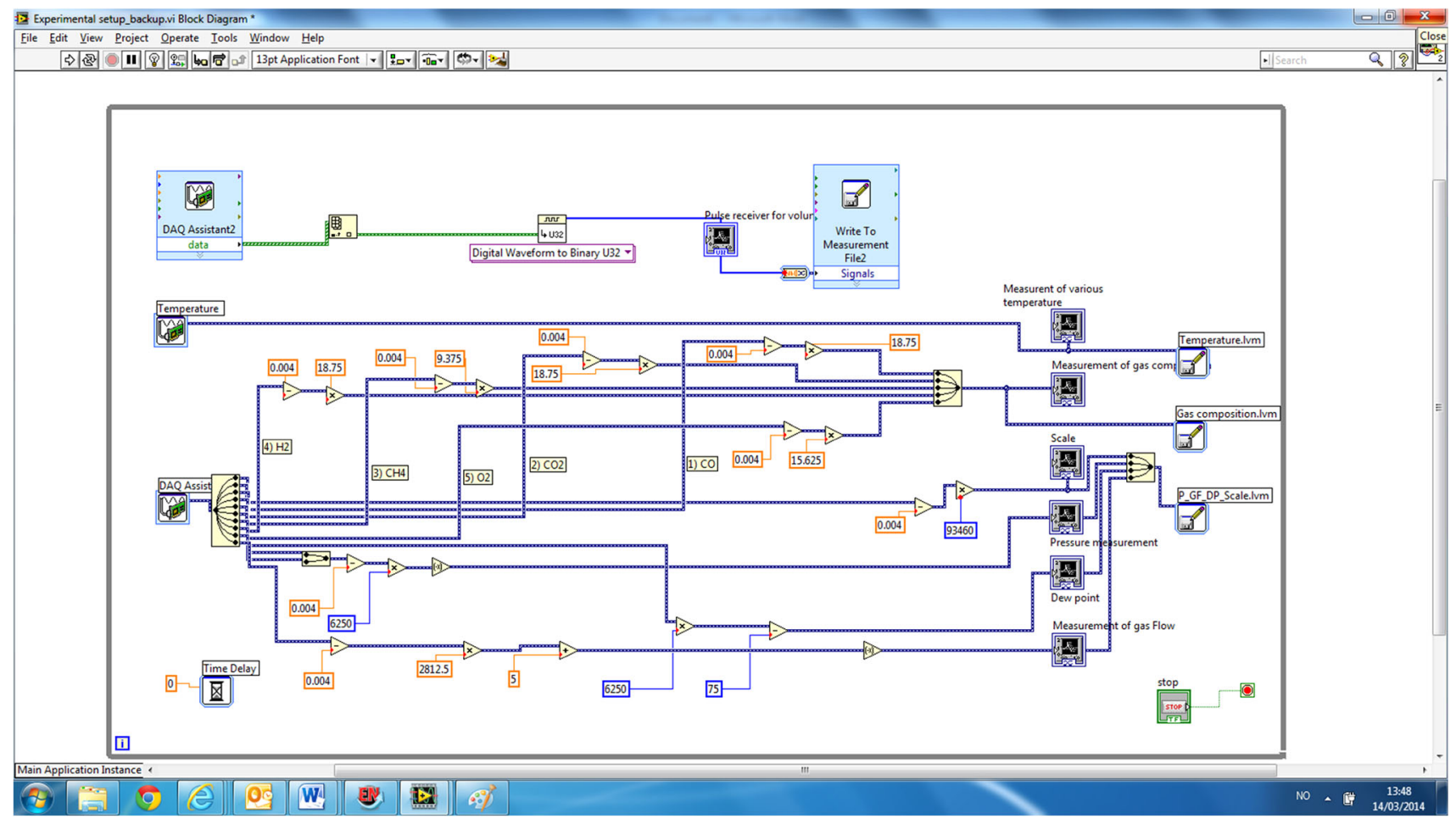




\section{References}

Ahmed I, Nipattummakul N, Gupta A (2011) Characteristics of syngas from co-gasification of polyethylene and woodchips. Appl Energy 88(1):165-174

Asadullah M (2014) Barriers of commercial power generation using biomass gasification gas: a review. Renew Sustain Energy Rev 29:201-215

Atnaw SM, Sulaiman SA, Yusup S (2014) Influence of fuel moisture content and reactor temperature on the calorific value of syngas resulted from gasification of oil palm fronds. Sci World J. doi:10. 1155/2014/121908

Barman NS, Ghosh S, De S (2012) Gasification of biomass in a fixed bed downdraft gasifier - a realistic model including tar. Bioresour Technol 107:505-511

Barrio M (2002) Experimental investigation of small-scale gasification of woody biomass. $\mathrm{PhD}$ dissertation, Norwegian University of Science and Technology, Trondheim, Norway

Basu P (2010) Biomass gasification and pyrolysis: practical design and theory. Academic press, USA

Brown RC, Brown TR (2013) Biorenewable resources: engineering new products from agriculture. John Wiley \& Sons, USA

Chopra S, Jain AK (2007) A review of fixed bed gasification systems for biomass. Agric Eng Int: CIGR J 9:1-26

Couto N, Rouboa A, Silva V, Monteiro E, Bouziane K (2013) Influence of the biomass gasification processes on the final composition of syngas. Energy Proced 36:596-606

Gautam G (2010) Parametric study of a commercial-scale biomass downdraft gasifier: experiments and equilibrium modeling. Dissertation, Auburn University, USA

Grønli MG (1996) A theoretical and experimental study of the thermal degradation of biomass. Dissertation, Norwegian University of Science and Technology, Trondheim, Norway

Hedberg E, Kristensson A, Ohlsson M, Johansson C, Johansson P-A, Swietlicki E, Vesely V, Wideqvist U, Westerholm R (2002) Chemical and physical characterization of emissions from birch wood combustion in a wood stove. Atmos Environ 36(30):4823-4837

Hindsgaul C, Schramm J, Gratz L, Henriksen U, Dall Bentzen J (2000) Physical and chemical characterization of particles in producer gas from wood chips. Bioresour Technol 73(2):147-155

Janajreh I, Al Shrah M (2013) Numerical and experimental investigation of downdraft gasification of wood chips. Energy Convers Manag 65:783-792

Jayah T, Aye L, Fuller R, Stewart D (2003) Computer simulation of a downdraft wood gasifier for tea drying. Biomass Bioenergy 25(4):459-469
Knoef HAM, Ahrenfeldt J, Angrill LS, Group NOvT-NOBT (2012) Handbook biomass gasification. BTG Biomass Technology Group, Netherlands

Kotowicz J, Sobolewski A, Iluk T (2013) Energetic analysis of a system integrated with biomass gasification. Energy 52:265-278

Lee U, Balu E, Chung J (2013) An experimental evaluation of an integrated biomass gasification and power generation system for distributed power applications. Appl Energy 101:699-708

Lenis Y, Osorio L, Pérez J (2013) Fixed bed gasification of wood species with potential as energy crops in Colombia: the effect of the physicochemical properties. Energy Sources, Part A: Recovery, Util Environ Eff 35(17):1608-1617

McKendry P (2002) Energy production from biomass (part 3): gasification technologies. Bioresour Technol 83(1):55-63

Moka VK (2012) Estimation of calorific value of biomass from its elementary components by regression analysis. BTech thesis, NIT Rourkela, India

Rajvanshi AK (1986) Biomass gasification. Altern Energy Agric 2:83-102

Reed T, Reed TB, Das A, Das A (1988) Handbook of biomass downdraft gasifier engine systems. Biomass Energy Foundation, USA

Shafiee S, Topal E (2009) When will fossil fuel reserves be diminished? Energy Policy 37(1):181-189

Shul'ga I, Zelenskii O, Vikhlyaev A (2012) Gasification of wood chips. Coke Chem 55(8):324-327

Son Y-I, Yoon SJ, Kim YK, Lee J-G (2011) Gasification and power generation characteristics of woody biomass utilizing a downdraft gasifier. Biomass Bioenergy 35(10):4215-4220. doi:10. 1016/j.biombioe.2011.07.008

Warren TJB, Poulter R, Parfitt RI (1995) Converting biomass to electricity on a farm-sized scale using downdraft gasification and a spark-ignition engine. Bioresour Technol 52(1):95-98. doi:10. 1016/0960-8524(95)00022-7

Wei L (2010) Technical and economic evaluation of small-scale biomass gasification facilities in Mississippi. PhD Dissertation, Mississippi State University, USA

Yoon H, Cooper T, Steinfeld A (2011) Non-catalytic autothermal gasification of woody biomass. Int $\mathrm{J}$ Hydrog Energy 36(13):7852-7860

Zainal ZA, Rifau A, Quadir GA, Seetharamu KN (2002) Experimental investigation of a downdraft biomass gasifier. Biomass Bioenergy 23(4):283-289. doi:10.1016/s0961-9534(02)00059-4 